\title{
eIProyecto BEPS de la OCDE y el Derecho Fiscal Internacional en Brasil(*)
}

\section{The BEPS Project of the OECD and the International Tax Law in Brazil}

\begin{abstract}
Resumen: En el presente artículo, el autor analiza el proyecto BEPS de la OCDE y sus implicancias dentro del Derecho Fiscal Internacional de Brasil, como el posible generador de una nueva etapa en la imposición internacional. En ese sentido, explica la política internacional brasilera, el contexto que motivó a la firma de Convenciones y el modelo que se siguió para el mismo. Asimismo, evalúa la importancia de la transparencia fiscal e intercambio de informaciones, conectado con las características de cooperación y competencia.
\end{abstract}

Palabras Clave: BEPS - Derecho Internacional Público - OCDE - Política Fiscal brasilera

\begin{abstract}
In this article, the author analyzes the BEPS project of the OECD and its implications in the International Tax Law of Brazil as a potential generator of a new stage in the international taxation. In that sense, he explains the Brazilian international policy, the context that led the signing of conventions and the model that was followed for it. Furthermore, he assesses the importance of the fiscal transparency and the exchange of information, aspects connected with the cooperation and competition.
\end{abstract}

Keywords: BEPS - Public International Law - OECD - Brazilian Tax Policy

\section{Introducción}

Con una red de treinta y dos Convenciones para Evitar la Doble Imposición de la Renta (en adelante, "CDI"), Brasil comenzó a firmar tratados internacionales en la década del sesenta del siglo pasado. La primera CDI brasilera a entrar en vigor fue la realizada con el Japón, que fue publicada en 1967.

(*) Licenciatura en Derecho Privado de la Universidad Federal Fluminense. Licenciado en Derecho por la Universidad Cândido Mendes. Maestría en Derecho (área de concentración "Derecho y Economía”) de la Universidad Gama Filho. Doctor en Derecho de la Universidad Gama Filho área de concentración “Derecho y Economía”) Profesor de Derecho Financiero y Tributario de la Universidade do Estado do Rio de Janeiro. Correo electrónico: sergio.andre@sarocha.com.br

${ }^{(* *}$ Nota del Editor: El artículo fue recibido el 08 de octubre de 2016 y aprobada su publicación el 09 noviembre del mismo año. 


\section{El Proyecto BEPS de la OCDE y el Derecho Fiscal Internacional en Brasil The BEPS project of the OECD and the International Tax Law in Brazil}

Como tratados internacionales, las CDI forman parte del Derecho Internacional Público y, así, están sujetas a lo dispuesto en la Convención de Viena sobre Derecho de los Tratados, que entró en vigor en Brasil en 2009, cuando fue publicado el Decreto 7.030(1).

Cuando comenzó a realizar tratados para evitar la doble imposición de la renta, Brasil adoptaba un sistema territorial de imposición de la renta de las empresas ${ }^{(2)}$. De esta forma, se percibe que, en principio, la realización de tratados solo podría ser desventajosa para Brasil desde una perspectiva recaudadora, ya que éste no tributaba a sus residentes en relación a hechos económicos ocurridos fuera de su territorio, viniendo el tratado a limitar su tributación en la fuente ${ }^{(3)}$.

Uno de los temas más controvertidos en imposición internacional, es aquel referente a los efectos de la realización de una CDI sobre inversiones extranjeras directas ("FDIForeign Direct Investment"), habiendo posiciones en el sentido de que tales tratados son favorables, neutros o hasta incluso, desfavorables.

Aquellos que sostienen que, la realización de una convención tributaria es positiva, como forma de atracción de inversiones extranjeras, mencionan entre sus principales efectos el hecho de que la existencia de un tratado de esta naturaleza confiere mayor seguridad al inversor no residente, además de señalar que los países firmantes del tratado adhieren a ciertos patrones impositivos globales ${ }^{(4)}$.

Al respecto de la controversia, se sabe que cuando Brasil inició la realización de las $\mathrm{CDI}$, lo hizo por motivo de la convicción de que tales tratados atraerían inversiones externas para Brasil. Esta orientación queda clara en los trabajos de autores como Francisco Dornelles, pionero de la imposición internacional en Brasil y negociador de las primeras convenciones brasileras ${ }^{(5)}$.

Aunque focalizado en la atracción de FDI para Brasil, el ímpetu brasilero en la firma de las CDI no descuidó la protección de la recaudación brasilera como país de fuente. No por otra razón el país siempre incluyó en sus tratados con países desarrollados cláusulas de Tax Sparing o Matching Credit, además de, jamás dejar de lado la tributación en la fuente de royalties o reducir significativamente su recaudación sobre dividendos 0 intereses ${ }^{(6)}$.

El comentario arriba ya muestra que, aunque atento a las tendencias de la tributación en otros países y a iniciativas como el Proyecto BEPS ("Base Erosion and Profit Shifting") de la OCDE, Brasil siempre buscó un camino propio en el campo de la imposición internacional. Por lo tanto, podemos dejar registrada la opinión en el sentido de que difícilmente el país adherirá integralmente a los resultados del Proyecto BEPS, siendo más probable que haga una adhesión puntual ("cherry-picking") en relación a lo que le parezca más interesante y compatible con la realidad nacional.

(1) Sobre el tema, véase Sergio Rocha, Interpretação dos Tratados para Evitar a Dupla Tributação da Renda, 2a ed. (São Paulo: Quartier Latin, 2013, 133-158).

(2) La tributación en bases universales solamente comenzó a ser aplicada a partir del 1 de enero de 1996, por fuerza del artículo 25 de la Ley 9.249/95.

(3) Véase Luis Eduardo Schoueri, "Contribuição à História dos Acordos de Bitributação: a Experiência Brasileira”, Revista Direito Tributário Atual 22, (2008, 267).

(4) Véase Michael Lang y Jeffrey Owens, "The Role of Tax Treaties in Facilitating Development and Protecting the Tax Base", WU International Taxation Research Paper Series 03 (2014, 6-7), http://papers.ssrn.com/sol3/papers.cfm?abstract id=2398438.

(5) Véase Francisco Oswaldo Neves Dornelles, "Acordos para Evitar a Dupla Tributação da Renda", (Revista de Direito Tributário 3, enero-marzo 1978, 253-4).

(6) El artículo 10 de la Ley 9.249/95 eximió el pago de dividendos, a residentes o no residentes, de tributación en Brasil por el Impuesto de Renta. 


\section{Sergio André Rocha}

El Proyecto BEPS marca el inicio de una nueva etapa en la imposición internacional.

Cronológicamente, y dejando de lado experiencias históricas longincuas, el Derecho Tributario Internacional surge con el nacimiento del Impuesto de Renta. Considerándose la consolidación de este tributo en las primeras décadas del siglo $X X$, no es de extrañarse que la primera fase del desarrollo del Derecho Tributario Internacional se ubique en el período anterior a la Primera Guerra Mundial.

En el período entre guerras, delante de la necesidad de recuperación económica de las naciones europeas, el Derecho Tributario Internacional comenzó a tomar forma bajo los auspicios de la Sociedad de las Naciones, que en 1928 publicó el primer modelo de tratado tributario del cual se tenga noticia ${ }^{(7)}$.

Los trabajos desarrollados en el ámbito de la Sociedad de las Naciones en la década del 20 del siglo pasado establecieron el patrón de la imposición internacional que, en cierta medida, aún se encuentra en vigor.

Fue después de la Segunda Guerra Mundial que el Derecho Tributario Internacional ganó mayor impulso, una vez más siendo parte de los esfuerzos de recuperación económica de los países involucrados en el conflicto armado. Manuel Pires llega a destacar tres diferentes estados de desarrollo de la imposición internacional: (i) un primero pre-Primera Guerra Mundial; (ii) un segundo en el entre guerras; y, (iii) un tercero post-Segunda Guerra, destacando, entretanto, que los desarrollos más significativos sobre la materia ocurrieron apenas en esta tercera fase ${ }^{(8)}$ (Pires 1989, 217).

Estos breves comentarios resaltan dos características fundamentales de la imposición internacional:
- El nacimiento de la imposición internacional tiene relación directa con la creación del Impuesto de Renta y su consolidación en las primeras décadas del siglo XX.

- El impulso inicial a las discusiones al respecto del tema fue dado por la idea de cooperación y la necesidad de fomentar el desarrollo económico, principalmente después de las Guerras Mundiales.

Dos eventos colocaron en jaque este modelo: la globalización y la reciente crisis financiera mundial.

En términos generales, el término globalización se refiere a la universalización de relaciones económicas globales (industriales, comerciales, de servicios, etcétera), con la eliminación o reducción de barreras al comercio internacional. Además, la globalización también abrió espacio para la transferencia internacional de tecnología e intangibles, además del movimiento de personas entre países.

La globalización también tuvo un impacto enorme sobre la imposición a la renta. La renta, en cuanto factor económico, se tornó altamente móvil. Cuando empresas operan en todo el mundo, la asignación de la renta para cada país donde una multinacional opera se vuelve un gran desafío(9). La movilidad de la renta fuerza a los países a asignar a la imposición sobre bases impositivas menos móviles, como el trabajo y el consumo(10),

(7) Véase Sergio Rocha, Interpretation of Double Taxation Conventions: General Theory and Brazilian Perspective (The Netherlands: Kluwer, 2009), 1-6.

(8) Véase Alberto Xavier, Direito Tributário Internacional do Brasil, 7a ed. (Rio de Janeiro: Forense, 2010$), 69$.

(9) Este aspecto ya era señalado por Marco Aurélio Greco, para quien "el problema clásico sobre el cual se inclinan los estudiosos y delante del cual las legislaciones de los diversos países buscaron crear mecanismos de neutralización era la movilidad de la renta. Se trata de una cuestión seria pues, en función de la movilidad de la renta, puede haber un vaciamiento de la base imponible en determinado país". (Marco Aurélio Greco, "Crise do Imposto de Renda na sua Feição Tradicional", en Estudos Tributários, org. Condorcet Rezende (Río de Janeiro: Renovar, 1999), 422-3.

(10) Véase Reuven S. Avi-Yonah, "Globalization, Tax Competition, and the Fiscal Crisis of the Welfare State." Harvard Law Review, Vol. 113 (2000, 1575-7). 


\section{El Proyecto BEPS de la OCDE y el Derecho Fiscal Internacional en Brasil The BEPS project of the OECD and the International Tax Law in Brazil}

distribuyendo de forma injusta la carga impositiva en la sociedad.

A lo largo de las últimas décadas, los países buscaron desarrollar mecanismos para prevenir la transferencia artificial de ganancias entre empresas del mismo grupo. Tales iniciativas generaron las reglas de precios de transferencia y de transparencia internacional. Entre tanto, hasta hoy tales intentos se mostraron, por lo menos en parte, ineficaces.

Los países que sufren los efectos dañinos de la transferencia artificial de ganancias también son, en alguna extensión, culpados por la misma. La OCDE viene dedicando esfuerzos para controlar la llamada Competencia Fiscal Perjudicial ("Harmful Tax Competition"). En su informe de 1998, la OCDE describió el problema de la siguiente manera:

"Este Informe visa desarrollar una mejor comprensión sobre como paraísos fiscales y regímenes fiscales preferenciales perjudiciales, referidas colectivamente como prácticas fiscales perjudiciales, afectan la ubicación de actividades financieras y otras actividades de servicios, erosionan la base fiscal de otros países, distorsionan el comercio y los patrones de inversión y perjudican la justicia, la neutralidad y la aceptación social de los sistemas impositivos en general. Tal competición fiscal perjudicial disminuye el bienestar global y perjudica la confianza de los contribuyentes en la integridad de los sistemas fiscales. El Informe reconoce la distinción entre regímenes fiscales perjudiciales aceptables y regímenes fiscales preferenciales perjudiciales y analiza cuidadosamente las características tanto de los Estados de residencia como de los Estados fuente que pueden llevar a los impactos dañinos de regímenes fiscales preferenciales perjudiciales. El Informe reconoce que hay limitaciones en las respuestas unilaterales o bilaterales a un problema que es intrínsecamente multilateral e identifica modos en los cuales gobiernos pueden establecer una estructura común en la cual los países puedan operar individualmente y colectivamente para limitar los problemas presentados por países y territorios fiscalmente soberanos actuando con prácticas fiscales perjudiciales" (OCDE 1998, 8).

Algunos de los regímenes fiscales preferenciales perjudiciales mencionados en el pasaje anterior son creados por "países de imposición regular". Por lo tanto, no es insólito que los mismos países que sufren de la competencia fiscal perjudicial también tengan sus propios regímenes fiscales preferenciales perjudiciales, creando, por lo tanto, una paradoja.

El ambiente económico post globalización mudó los patrones de la imposición internacional. Si, al comienzo, el objetivo principal de los tratados internacionales impositivos era evitar la doble tributación, en una economía globalizada los objetivos más importantes de tales tratados se convirtieron a combatir la competencia fiscal perjudicial, promover la transparencia y controlar la evasión fiscal y el planeamiento fiscal abusivo. Con el desarrollo de medidas unilaterales y domésticas para evitar la doble tributación, esta dejó de ser la prioridad de los tratados internacionales, habiendo, inclusive, quien sostenga que tales convenciones tal vez no sean más necesarias (Easson 2000, 619).

Después de la crisis económica iniciada en 2008 y el empobrecimiento de los países desarrollados, especialmente en Europa, la necesidad por recetas tributarias se acentuó. La transparencia se volvió el lema. La batalla contra los paraísos fiscales y regímenes fiscales preferenciales entró en una nueva etapa. El planeamiento impositivo agresivo se volvió blanco. En algunos países, como Inglaterra, multinacionales fueron juzgadas en el tribunal de la opinión pública, acusadas de responsables por los cortes en programas de asistencia social. Algo parecido ocurre hoy en Australia.

Una vez más un ambiente económico en evolución requiere cambios en la imposición internacional. Una economía global exige una administración impositiva global. La mayoría de los países occidentales tributan a sus residentes en bases mundiales. Con todo, la administración impositiva sigue territorial. Surge una nueva paradoja. Los mismos países que compiten por recetas impositivas deben 


\section{Sergio André Rocha}

cooperar entre sí para enfrentar los desafíos presentados por las multinacionales en el siglo XXI. El principio de la transparencia se vuelve uno de los pilares más relevantes de la imposición internacional en esta nueva era, junto con el principio de la cooperación (Rocha 2015, 58-67).

Hechos estos comentarios introductorios, pasamos a analizar los temas que nos fueron propuestos en los siguientes tópicos. Destacamos, desde ya, que todas las transcripciones de textos cuyo original fue escrito en lengua inglesa y portuguesa fueron libremente traducidas por el autor.

\section{Política Internacional brasilera de realización de tratados: fuente o residencia}

Como mencionamos en el pasaje anteriormente, Brasil tiene una clarísima tendencia a la preferencia del principio de la fuente en sus tratados internacionales. La doctrina brasilera normalmente afirma, de forma categórica, que las CDI brasileras siguen el Modelo de Convención de la OCDE ${ }^{(11)}$. Con todo, un análisis más detenido de los tratados firmados por Brasil(12) muestra que, de hecho, los mismos son mucho más próximos del Modelo de la ONU que del Modelo de la OCDE, en la medida en que sus reglas distributivas normalmente se distancian de este y se aproximan a aquel.

Luis Eduardo Schoueri señala, con razón, que Brasil es un país que consiguió, con éxito, establecer una política propia de realización de tratados internacionales. En nuestra opinión, los países latinoamericanos deberían retomar la tradición en dirección a la imposición en la fuente.

En las últimas décadas, la teoría de los elementos de conexión fue modificándose. La noción de fuente, principalmente, pasó a englobar todas las formas de exploración y actuación en el mercado de un determinado país. Con los desarrollos tecnológicos, una revolución en la teoría de los elementos de conexión se inició. La exploración del mercado de un país debe ciertamente legitimar su competencia para tributar la renta generada ${ }^{(13)}$, siendo necesario que los tratados, bilaterales o multilaterales, reconozcan esta nueva realidad.

\section{Interpretación de tratados internacionales impositivos en Brasil}

Brasil todavía no tiene un gran histórico de controversias relacionadas a la aplicación de tratados internacionales impositivos. Los principales casos siendo apreciados por los tribunales se refieren a los siguientes temas:

- Aplicación del artículo 7 de los tratados realizados por Brasil (Ganancias de las Empresas) para bloquear la regla brasilera de imposición automática de ganancias no distribuidas por empresas controladas en el exterior (Rocha 2014, 50-53).

- Aplicación del artículo 7 de las CDI brasileras para evitar la incidencia del Impuesto de Renta Retenido en la Fuente sobre el pago de servicios técnicos sin transferencia de tecnología (Rocha 2012, 267-289).

- Aplicación del artículo 24 ("No Discriminación") de la Convención firmada con Suecia para evitar la imposición en la fuente sobre dividendos en razón de los mismos no ser tributados cuando pagados para residentes en Brasil (Rocha 2007, 72-104).

(11) Véase Alberto Xavier, Direito Tributário Internacional do Brasil, 7a ed. (Río de Janeiro: Forense, 2010$), 72$.

(12) Para un análisis de las disposiciones de los tratados realizados por Brasil, véase Luís Eduardo Schoueri, Natalie Matos Silva, Brazil. Pasquale Pistone y otros, coords., The Impact of the OECD and UN Model Conventions on Bilteral Tax Treatie (New York: Cambridge University Press, 2012), 171-202; Jonathan Barros Vita, "As Convenções para Evitar a Dupla Tributação Brasileiras: Técnicas de Negociação e Análise Estrutural Segundo os Modelos OCDE e ONU”, Revista Direito Tributário Atual 24 (2010, 303-19).

(13) Véase Victor Uckmar, Marco Aurélio Greco y Sergio André Rocha, Manual de Direito Tributário Internacional (São Paulo: Dialética, 2012, 285-6). 


\section{El Proyecto BEPS de la OCDE y el Derecho Fiscal Internacional en Brasil The BEPS project of the OECD and the International Tax Law in Brazil}

- Aplicación del artículo 2 ("Impuestos Visados") para incluir en el alcance objetivo de los tratados firmados por Brasil contribuciones como la Contribución Social sobre la Ganancia ("Contribuição Social Sobre o Lucro Líquido"), la CIDE-Tecnología y el PIS/COFINS-Importación (Rocha 2015, 557-561).

Como mencionamos arriba, aunque los tratados brasileros se aproximen mucho más al Modelo de Convención de la ONU, hay un entendimiento generalizado en el país de que los tratados brasileros seguirían el Modelo de la OCDE. La propia Receta Federal de Brasil, en más de una oportunidad, se manifestó en este sentido.

En la Solución Interna COSIT No. 18/2013, la Receta Federal de Brasil sostuvo expresamente que las convenciones brasileras "usualmente tienen como base la Convención Modelo de la OCDE". Ya en la Solución de Divergencia COSIT de $8 / 2013$, la Receta Federal fue aún más asertiva en cuanto a la influencia de la Convención Modelo de la OCDE sobre los tratados brasileros. En sus palabras,

"Ios acuerdos o convenciones para evitar la doble imposición deben ser interpretados como norma especial $y$, de este modo, prevalecen sobre la norma interna de cada Estado en lo que esta le fuera contraria en relación al caso concreto. En este sentido, en la Convención Modelo de Imposición de la Renta y del Capital de la Organización de Cooperación para el Desarrollo Económico (OCDE), modelo que sirvió de base para los acuerdos para evitar la doble imposición en que Brasil es signatario, tiene dos métodos para la eliminación de la doble imposición".

En relación a este aspecto, nos parece que hay un equívoco, tanto de la doctrina como de las decisiones. Los tratados brasileros siguen de cerca la tradición latinoamericana de buscar mayores poderes impositivos para el país de fuente y, en ese sentido, se separa de la lógica de la Convención Modelo de la OCDE de privilegiar la imposición en el país de residencia.

De todas formas, una vez que prevalece el entendimiento de que las convenciones brasileras se basan en el Modelo de la OCDE, es común que los Comentarios de la OCDE sean utilizados en decisiones y en trabajos académicos. No es atribuido a tales Comentarios cualquier carácter vinculante, sea como contexto, sea atribuyéndoles el carácter de lenguaje especial(14). La posición que prevalece en Brasil fue bien sintetizada por Alberto Xavier, quien afirma que "el peso interpretativo de los Comentarios no puede, pues, ir más allá del que se reconoce a la mejor doctrina" (Xavier 2010, 136).

Hay que notar, con todo, que la discusión al respecto de la utilización de los Comentarios se presenta bastante superficial en Brasil. Por ejemplo, no conocemos ningún precedente, administrativo o judicial, donde la cuestión referente a su utilización estática (uso de los Comentarios en vigor cuando la realización del tratado) o dinámica (uso de los Comentarios en vigor cuando la aplicación del tratado) haya sido abordada ${ }^{(15)}$.

\section{Solución de controversias resultantes de tratados: el procedimiento amigable}

Se sabe que el principal instrumento para la solución de controversias en el contexto de las CDI es el llamado procedimiento amigable ${ }^{(16)}$. Brasil no tiene cualquier tradición o práctica (al

(14) Véase Sergio André Rocha, Interpretation of Double Taxation Conventions: General Theory and Brazilian Perspective (The Netherlands: Kluwer, 2009), 128-37.

(15) Véase Sergio André Rocha, Interpretation of Double Taxation Conventions: General Theory and Brazilian Perspective (The Netherlands: Kluwer, 2009), 136-7.

(16) Véase Sergio André Rocha, Interpretation of Double Taxation Conventions: General Theory and Brazilian Perspective (The Netherlands: Kluwer, 2009), 172-88; Fernando Serrano Antón, La Resolución de Conflictos en el Derecho Internacional Tributario: Procedimiento Amistoso y Arbitraje (Navarra: Civitas, 2010), 125-287. 


\section{Sergio André Rocha}

menos pública) con procedimientos amigables. Desde 2008, la Convención Modelo de la OCDE pasó a prever, en su artículo 25 (5), el arbitraje como forma de solución de controversias, en los casos en que el procedimiento amigable no produce resultados. A partir de 2011, la Convención Modelo de la ONU incorporó también una regla de arbitraje mandatorio. Brasil no posee ningún tratado con cláusula de arbitraje, ni se espera que venga a tener en el futuro próximo(17).

\section{Transparencia fiscal e intercambio de informaciones}

Una de las áreas más importantes de la imposición internacional contemporánea es, la transparencia fiscal y el intercambio de informaciones para fines fiscales. Este es un campo donde el liderazgo de la OCDE y de su Foro Global sobre Transparencia e Intercambio de Informaciones para Fines Fiscales es innegable (Rocha 2015, 25-33). Brasil sigue esta tendencia. En 2011, el país firmó la Convención Multilateral sobre Asistencia Administrativa Mutua en Asuntos Fiscales, cuya tramitación en el Congreso Nacional se inició apenas en 2014.

En 2009, Brasil pasó a integrar el Foro Global. Creado en 2000 como un grupo ad hoc de la OCDE, actualmente el Foro Global cuenta con más de ciento veinte países y ha trabajado fuertemente para el desarrollo y la aplicación de patrones globales de transparencia fiscal.

El Foro tiene sus actividades futuras coordinadas por un Steering Group, en cuanto un Peer Group es responsable por conducir revisiones de los sistemas legales de los propios países miembros, buscando verificar su adecuación a los patrones internacionales de intercambio de informaciones fiscales. Brasil es miembro de ambos grupos.

Las revisiones realizadas por el Peer Group son desarrolladas en dos fases. En la primera fase, es examinado el ordenamiento jurídico del país, con vistas a determinar si este hace viable el intercambio de informaciones fiscales. Ya en la segunda fase se revisa la implementación práctica de tales reglas.
En 2011, Brasil fue revisado, en la primera fase, por el Peer Group. En abril de 2012, el Foro Global divulgó un informe de la revisión brasilera.

Tal revisión buscó identificar la base regulatoria de Brasil para el intercambio de informaciones fiscales entre nuestro Fisco y las autoridades fiscales de otros países, teniendo atención principal: (i) a la disponibilidad de la información; (ii) al acceso a la información; y, (iii) a las reglas específicas, domésticas e internacionales (tratados realizados por Brasil) sobre intercambio de informaciones.

De una forma general, la conclusión del informe del Peer Group del Foro Global fue positiva, reconociendo que la legislación brasilera posee reglas que dan viabilidad a las autoridades fiscales acceso a las informaciones referentes a contribuyentes y transacciones, inclusive operaciones bancarias, de modo que Brasil estaría en condiciones de atender a las solicitudes de informaciones hechas por otros países (OECD 2012, 7).

En lo que se refiere a la disponibilidad de las informaciones, la única excepción de los revisores fue en cuanto a la posibilidad del sigilo que protege informaciones obtenidas por abogados viniera a ser un obstáculo a la obtención de informaciones solicitadas por otro país (OECD 2012, 76). En este particular, parece no tener cabida la posición del Peer Group, ya que el sigilo profesional de los abogados, que es esencial a la justicia, no puede ser dejado de lado por cuenta de los intereses fiscales de autoridades nacionales o extranjeras. Además de esto, es difícil imaginar una situación en que determinada información

(17) Véase Sergio André Rocha, Interpretação dos Tratados para Evitar a Dupla Tributação da Renda, 2ª ed. (São Paulo: Quartier Latin, 2013), 282-90. 


\section{El Proyecto BEPS de la OCDE y el Derecho Fiscal Internacional en Brasil The BEPS project of the OECD and the International Tax Law in Brazil}

fiscal solamente exista en las manos del abogado del sujeto pasivo.

Otra crítica, desde nuestro punto de vista infundada, fue referente a la obligación de notificación del contribuyente antes que la autoridad fiscal pueda tener acceso directo a informaciones bancarias (OECD 2012, 59). Ahora, si aún hay serias dudas al respecto de la propia constitucionalidad de la quiebra de sigilo bancario por el Fisco (Rocha 2015, 194-195), no se puede imaginar que la intimación previa del contribuyente pueda ser separada por causa de intereses de la administración fiscal de otro país.

Fuera estos comentarios, los puntos levantados por el Peer Group fueron pertinentes. El intercambio de informaciones por las autoridades brasileras está previsto en los treinta y dos tratados tributarios brasileros en vigor. Sin embargo, como tales tratados fueron firmados en momentos distintos, la redacción de la regla de intercambio de informaciones no es homogénea y ni siempre sigue el patrón previsto en el modelo de la OCDE. De esta forma, los revisores señalaron la necesidad de hacerse diversos ajustes de redacción en las reglas de algunos tratados brasileros para que las mismas se amolden al patrón internacional (OECD 2012, 61).

Un punto procedente, señalado durante la revisión, se refiere a la demora para que los tratados internacionales realizados por Brasil entren en vigor. Como es notado por el Peer Group, normalmente se llevan años para que un tratado firmado por Brasil efectivamente entre en vigor y sea aplicable (OECD 2012, 82). Aquí no hay cómo cuestionarse la opinión formalizada en la revisión de la armadura legislativa brasilera.

El 31 de julio de 2013 fue divulgado el informe de la segunda fase de la revisión por el Peer Group. Considerando que la Receta Federal de Brasil no divulga cualquier información sobre los procedimientos de intercambios de informaciones por Brasil, este informe es la mejor oportunidad para que tengamos algún conocimiento sobre las prácticas adoptadas por las autoridades fiscales en esta área(18).
Según el informe del Foro Global, en el período de tres años revisados, entre 2009 y 2011, Brasil recibió 89 pedidos de informaciones, de los cuales 18 fueron respondidos en 90 días, 23 fueron respondidos entre 91 y 180 días, 20 casos respondidos entre 181 días y un año, 13 solicitudes fueron respondidas en más de un año, en cuanto 15 pedidos permanecían en abierto (OECD 2013, 9). En el mismo período, Brasil envió pedidos de información en 7 casos, a 4 países diferentes (OECD 2013, 89). Aunque algunos de los países que solicitaron informaciones hayan reclamado la demora de la respuesta y la falta de actualizaciones sobre el status de la solicitud, de una forma general los comentarios sobre Brasil fueron positivos (OECD 2013, 9).

Uno de los aspectos destacados por el informe fue un cambio ocurrido en los procedimientos internos de la Receta Federal frente a pedidos de intercambio de informaciones. Ahora, cuando la autoridad competente no posee la información, transfiere la solicitud directamente para la autoridad regional, que tiene mejores condiciones para obtener las informaciones sobre el sujeto pasivo. De acuerdo con el informe, este procedimiento estaría siendo adoptado desde enero de 2013 y, desde su implementación, todas las solicitudes habrían sido atendidas en un plazo más corto (OECD 2013, 21-22).

La disponibilidad de las informaciones fue uno de los puntos positivos señalados por el Peer Group. Según el informe, de un modo general, las informaciones están disponibles, sea con autoridades públicas (Receta Federal, Banco Central, Comisión de Valores Mobiliarios, Registro Civil de las Personas Jurídicas, Junta

(18) Es un tema permeado por el principio de la transparencia, hay que reconocerse que hay pocas áreas en que la actuación de la Receta Federal de Brasil sea más opaca de lo que en relación a la tributación internacional en general y al intercambio de informaciones en particular. Las autoridades fiscales no hacen disponible ninguna información al público sobre sus prácticas y procedimientos en esta área. 


\section{Sergio André Rocha}

Comercial, etcétera), sea con la propia entidad, o con terceros, como instituciones financieras (OECD 2013, 23).

Uno de los aspectos sensibles del intercambio de informaciones se refiere a la transferencia de datos que estén disponibles apenas para instituciones financieras, pasando por el debate al respecto del sigilo bancario.

Durante los tres años revisados por el Foro Global, Brasil recibió 10 pedidos de información bancaria. En 4 casos, la Receta Federal ya tenía la información solicitada y en 6 tuvo que pedir la información al sujeto pasivo (OECD 2013,66). De todas formas, el procedimiento que Brasil ha adoptado en los casos de solicitud de informaciones bancarias ha sido: (i) verificar la disponibilidad de la información en el sistema de la Receta; (ii) solicitar la información al sujeto pasivo; y, (iii) buscar la información junto a la institución financiera que la tenga (OECD 2013, 67).

El equipo revisor señaló que la cuestión del quiebre de sigilo bancario es aún controvertido en Brasil, pendiente de decisión final por el Supremo Tribunal Federal. Con todo, el informe hizo cuestión en destacar que los países no deben negase a suministrar información con base en sus reglas sobre sigilo (bancario, societario o profesional). De todas formas, en cuanto el Supremo Tribunal Federal no se pronuncia sobre el asunto, en la visión del Foro Global, la regla de la Ley Complementaria $105 / 2001^{\left({ }^{(19)}\right.}$ se encuentra en vigor y hace viable la obtención de informaciones junto a instituciones financieras por las autoridades fiscales brasileras (OECD 2013, 76).

Analizándose el informe, es posible notar una preferencia por la eficacia del intercambio de informaciones en comparación al mantenimiento de derechos de notificación y participación del sujeto pasivo.

La revisión de la práctica brasilera también pasó por el examen de las convenciones realizadas por Brasil. Fueron indicadas modificaciones que deberían ser hechas en algunos tratados para que estos estén de acuerdo con el patrón de la OCDE. En todos los casos, fue identificado que Brasil ya estaría en contacto con el otro país para hacer los ajustes necesarios en el tratado respectivo (OECD 2013, 87). En este punto fue hecha, nuevamente, crítica al tiempo que se lleva aquí entre la firma del tratado y a su aprobación final por el Congreso Nacional (OECD 2013, 100).

\section{El problema de la erosión de bases tributables y de la transferencia de ganancias}

Como ya señalamos, uno de los grandes problemas actuales de la imposición internacional es la gran paradoja entre cooperación y competencia. Los mismos países que luchan para mantener altos niveles de recaudación y combaten contra planeamientos impositivos agresivos engendrados por las empresas multinacionales, compiten por recetas tributarias creando beneficios fiscales y regímenes fiscales privilegiados para atraer a los mismos capitales. Este aspecto fue resaltado por Thomas Piketty en su aclamado El Capital en el Siglo XXI:

"[...] Al mismo tiempo, el aumento de la competencia fiscal a lo largo de las últimas décadas, en un contexto de libre competencia de capital, llevó a un desarrollo sin precedentes de regímenes derogatorios en relación a la renta del capital, que en casi todo el mundo escapa por ahora del cálculo de la progresividad del impuesto sobre la renta. Esto es particularmente válido para Europa, dividida entre Estados de pequeño tamaño que, hasta el momento, se muestran incapaces de desarrollar un mínimo de coordinación en materia fiscal. El resultado es una disputa sin fin para reducir especialmente el impuesto sobre las ganancias de las empresas y para exentar los intereses, dividendos y otras rentas financieras del régimen normal de tributación al cual son sometidas las rentas del trabajo" (Piketty 2014, 483).

(19) Esta ley estableció la posibilidad de acceso de las autoridades fiscales a las informaciones bancarias de dos contribuyentes. 
Como los países tributan a sus residentes en bases mundiales, pero ejercen sus competencias fiscalizadoras apenas en su territorio, sin la cooperación de los demás países, aquellos tendrán limitados instrumentos para volverse eficaces sus regímenes tributarios domésticos (Rocha 2015, 62-67).

El principio de la cooperación entra en escena y pasa a exigir gran compromiso político de todos los países involucrados, sin lo cual, no se mostrará posible alcanzar los ambiciosos resultados del Proyecto BEPS.

La crisis económica iniciada en 2008, y aún no enteramente disipada, colocó en riesgo a los modelos de seguridad social y previdencia de los países más desarrollados. De cierta forma, como se vio en el avance del Reino Unido contra empresas tales como Amazon, Google y Starbucks, los Estados buscaron colocar buena parte de la culpa por la crisis y la necesidad de revisión de derechos en las empresas multinacionales. En la corte de la opinión pública, las empresas fueron consideradas culpadas.

Este ambiente creó el contexto propicio para el lanzamiento del Proyecto BEPS.

Sin embargo, nos parece que los responsables o "culpables" por la situación actual de la imposición internacional fueron principalmente los estados, que crearon una espiral de competencia fiscal que volvió posible la actuación de las empresas multinacionales. Si hubiera una mayor coordinación de los países, una parte significativa de los planeamientos fiscales internacionales envolviendo erosión de base impositiva y transferencia de ganancias no sería posible.

Los destinatarios del BEPS parecen ser los países, una vez que los resultados del Proyecto de la OCDE no serán aplicables directamente a las empresas, dependiendo de actuaciones de los Poderes Ejecutivo y Legislativo de los países -al menos por medio de la realización y aprobación de tratados internacionales.

\section{Del bilateralismo al multilateralismo en la imposición internacional}

El Derecho Tributario Internacional del siglo XX se desarrolló sobre una base bilateral, estructurándose primariamente sobre convenciones bilaterales realizadas entre países. Una de las características de la imposición internacional del siglo XXI, al menos de la manera como se viene diseñando en el Proyecto BEPS, es que la misma pasará a depender en gran parte de iniciativas multilaterales $^{(20)}$. Conforme lo observado por Caio Augusto Takano:

"La necesidad de una solución multilateral, con base en la cooperación entre Estados soberanos, ganó evidencia y pasó a ser reconocida como necesaria no apenas por la doctrina, como también por la propia OCDE. En este punto reside una fuerte tensión entre la necesidad de armonización y cooperación internacional y el derecho de los Estados moldear sus legislaciones tributarias libremente, con base en su soberanía" (Takano 2014).

El desarrollo de un instrumento multilateral es parte del Proyecto BEPS. La Acción 15 del Proyecto cuida del tema. En el informe publicado en 2014, la OCDE así resumió el trabajo desarrollado en este campo:

"La Acción 15 del Plan de Acción BEPS establece un análisis de las cuestiones de Imposición internacional y Derecho Internacional Público relacionadas al desarrollo de un instrumento multilateral que permita que los países que lo deseen

(20) Véase Pasquale Pistone, "Coordinating the Action of Regional and Global Players during the Shift from Bilateralism to Multilateralism in International Tax Law", World Tax Journal 6 (febrero 2014): 3-4; Yariv Brauner, "BEPS: An Interim Evaluation", World Tax Journal 6 (febrero 2014): 37. 


\section{Sergio André Rocha}

implementen medidas desarrolladas durante el curso del trabajo sobre BEPS y en tratados bilaterales aumentados. Con base en este análisis, países interesados desarrollarán un instrumento multilateral diseñado para suministrar un abordaje innovador para temas de imposición internacional, reflejando la naturaleza dinámica de la evolución de la economía global y la necesidad de adaptarse rápidamente a esta evolución" (OECD 2014, 10).

Se ve, por lo tanto, que el Proyecto BEPS depende esencialmente de instrumentos de Derecho Internacional Público, sea mediante alteración de tratados bilaterales existentes, sea mediante la realización de nuevos tratados multilaterales. En el caso brasilero, la entrada de un tratado internacional en vigor depende no solo de la participación del Poder Ejecutivo, que tiene la competencia para realizar tratados internacionales ${ }^{(21)}$, pero también del Poder Legislativo, a quien cabe su aprobación ${ }^{(22)}$.

Vale la pena resaltar, con todo, que ninguna obligación directa para contribuyentes localizados en Brasil podrá ser creada por la vía convencional. Las obligaciones impositivas, sean materiales, sean formales, están sujetas al principio de la legalidad ${ }^{(23)}$, de modo que la creación de cualquier nueva obligación para los contribuyentes residentes en Brasil deberá ser establecida por leyes domésticas, de modo que no se vislumbra que las acciones resultantes del Proyecto BEPS puedan ser una excepción al primado del "no taxation without representation" -obviamente, empresas brasileras actuando en el exterior tendrán que adaptarse a las reglas vigentes donde estén sus operaciones.

En nuestra opinión, la existencia de un arreglo multilateral para el tratamiento de grandes cuestiones como la transparencia fiscal internacional, mayor armonización de las reglas de precios de transferencia y el combate a la evasión fiscal y al planeamiento tributario agresivo, no significa que los tratados tributarios bilaterales serán sustituidos por convenciones multilaterales.

Con efecto, nos parece que la división de recetas tributarias sobre transacciones internacionales seguirá siendo eminentemente una cuestión a ser definida bilateralmente entre los países, resaltándose, ahí, la importancia de que los países latinoamericanos sigan defendiendo políticas tributarias coherentes con sus intereses domésticos.

Creo que informaciones sobre la carga tributaria efectiva soportada por las empresas multinacionales en cada jurisdicción son datos relevantes para descubrir planeamientos tributarios agresivos, y orientar la actuación de los legisladores y autoridades fiscales domésticas para la adopción de medidas para evitar que tal fuga de la tributación ocurra. Con todo, no vemos como factible la adopción de algún modelo formular ("formulary apportionment") que pretenda asignar a cada país la receta tributaria definida a partir de algún criterio internacionalmente definido(24).

De esta forma, no vemos como factible el surgimiento de incompatibilidades relevantes entre los esfuerzos multilaterales y las convenciones bilaterales, al menos no como regla. Es posible, eso sí, que convenciones específicas tengan reglas de excepción que contradigan directrices contenidas en un tratado multilateral.

Por ejemplo, las convenciones brasileras realizadas con Dinamarca ${ }^{(25)}$, la República

(21) Artículo 84, VIII de la Constitución Federal.

(22) Artículo 49, I, de la Constitución Federal.

(23) Artículo 5o, Il y artículo 150, I de la Constitución Federal.

(24) Para mayores informaciones cerca del "formulary apportionment", Véase André Martins de Andrade, Tributação Internacional da Renda Empresarial (Belo Horizonte: Editora Fórum, 2008), 303-31.

(25) En el caso del tratado con Dinamarca, fue firmado un nuevo Protocolo excluyendo la regla. Con todo, el Protocolo aún no fue aprobado por el Congreso Brasilero y, por lo tanto, no está en vigor. 


\section{El Proyecto BEPS de la OCDE y el Derecho Fiscal Internacional en Brasil The BEPS project of the OECD and the International Tax Law in Brazil}

Eslovaca y la República Checa poseen dispositivos que vedan la aplicación de reglas CFC en el caso de empresas controladas ubicadas en estos países. Estos dispositivos específicos podrían ser considerados contrarios a la orientación adoptada en una convención multilateral. No obstante, entendemos que, en este caso, la regla bilateral, siendo más específica que la prevista en el convenio multilateral, deberá prevalecer hasta que sea modificada.

De esta forma, la opinión aquí sustentada es en el sentido de que la convención multilateral convivirá con los tratados bilaterales. Es posible que sean necesarios algunos ajustes en las $\mathrm{CDI}$, entretanto, caso haya reglas específicas en tratados bilaterales en sentido expresamente contrario de aquellas previstas en tratado multilateral aquellas deberán prevalecer hasta que sean revistas. Con todo, destacamos la opinión de que deben ser excepcionales las situaciones donde se notará un conflicto directo entre la regla contenida en el tratado bilateral y aquella prevista en la convención multilateral.

\section{8. ¿Existe un problema de erosión de base tributable y transferencia de ganancias en el Brasil?}

Una cuestión interesante es, si la erosión de la base tributaria y de la transferencia de ganancias es realmente un problema en el país. De hecho, es imposible decir que tales prácticas no ocurran en Brasil. Con todo, tenemos la impresión de que tales cuestiones han sido satisfactoriamente controladas por la legislación tributaria brasileira -por lo menos en gran parte de los casos.

En 2013, la Organización de las Naciones Unidas creó un Subcomité sobre BEPS para Países en Desarrollo, habiendo solicitado informaciones de diversos países, entre los cuales a Brasil. Una de las cuestiones presentadas a las autoridades fiscales brasileras fue cuáles son las prácticas o estructuras (de BEPS) más comunes usadas en su país o región, y cuáles las respuestas a ellas?. La respuesta de las autoridades brasileras fue la siguiente:

"Las prácticas más comunes adoptadas en Brasil con vistas a la erosión de base tributaria y transferencia de ganancias para países con tributación favorecida o que no permitan acceso a información relacionada a la estructura de capital, propiedad de activos o derechos, o transacciones económicas hechas con terceros son: (i) precios ficticios en la importación o exportación de mercaderías, servicios y derechos entre partes relacionadas (transfer pricing); (ii) arreglos societarios; (iii) deudas artificiales entre empresas del mismo grupo para generar gastos indebidos en empresas brasileras en operaciones mutuas; (iv) transacciones ficticias con residentes en países con tributación favorecidas o bajo regímenes fiscal privilegiados, así como con jurisdicciones que impongan restricciones al intercambio de informaciones con la administración fiscal brasilera; y, (v) transferencia artificial de residencia fiscal para evitar tributación en Brasil.

Para combatir estas prácticas, la legislación brasilera limita la deducción de royalties y establece la retención en la fuente sobre pagos relacionados a pagos de royalties y servicios, para evitar la dupla no imposición.

Adicionalmente, Brasil implementó reglas como: (i) control de precios de transferencia; (ii) reglas de thin capitalization; (iii) aumentó la alícuota de retención en la fuente en el caso de transacciones con países con tributación favorecida o que no sean transparentes; (iv) previsión de requisitos adicionales para permitir la deducción de gastos resultantes de transacciones con países con tributación favorecida o bajo regímenes fiscales privilegiados; $y$, (v) previsión de límites para la transferencia de residencia de contribuyentes brasileros para países o dependencias considerados paraísos fiscales o bajo regímenes fiscales privilegiados, así como jurisdicciones que impongan restricciones para la obtención de informaciones relevantes para la administración fiscal brasilera" (Naciones Unidas).

Se percibe que, por más que las autoridades fiscales brasileras indiquen BEPS como un problema, luego en la secuencia enumeran 


\section{Sergio André Rocha}

una larga lista de medidas adoptadas por la legislación doméstica de Brasil para combatir la erosión de base tributable y la transferencia de ganancias.

Así, si no es posible afirmar que la cuestión del BEPS no es un problema en Brasil; por otro lado, hay que reconocerse que la legislación doméstica del país redujo significativamente los efectos del problema.

Brasil tiene hoy probablemente las más abarcadoras reglas CFC del mundo ${ }^{(26)}$, cuyo único punto débil es que no son aplicables a personas físicas. El país también desarrolló su propio modelo de reglas de precios de transferencia, y posee altísima tributación sobre operaciones de importación de servicios y pagos de royalties para el exterior, la cual es aumentada en el caso de pagos para paraísos fiscales. Además, Brasil posee significativas reglas de limitación de deducibilidad de gastos en el caso de pagos para paraísos fiscales o entidades bajo regímenes fiscales privilegiados. En 2010, el país instituyó sus reglas de subcapitalización. Todas las reglas previstas en la legislación brasilera reducen significativamente el campo para la erosión de base tributable y la transferencia de ganancias.

A partir de una perspectiva brasilera, parece que el problema base del Proyecto BEPS es un problema principalmente de países desarrollados. Los reflejos de los resultados del Proyecto en la legislación doméstica brasilera deben ser limitados y puntuales.

En su respuesta al Subcomité de las Naciones Unidas sobre BEPS, las autoridades fiscales brasileras afirmaron que, de su perspectiva, las acciones del Proyecto más importantes para Brasil serían la 4 (Interest Deduction), la 8 (Transfer Pricing-Intangibles), la 9 (Transfer Pricing-Risk \& Capital), la 10 (Transfer Princig-High Risk Transactions), la 12 (Disclosure of Aggressive Tax Planning) y la 13 (Transfer Pricing Documentation).
Se nota que la mayoría de las acciones señaladas como relevantes por la autoridad fiscal brasilera se refiere a precios de transferencia. Por otro lado, se sabe que Brasil sigue un modelo de control de precios de transferencia que se distancia del modelo de la OCDE. No es de esperarse que Brasil venga a convergir sus reglas de precios de transferencia en dirección al modelo seguido por la OCDE. De esta forma, lo que se puede antever es que Brasil probablemente adoptará lo que le parezca interesante, a partir de los resultados del Proyecto BEPS, no siendo probable una incorporación integral de las determinaciones de la OCDE al fin del Proyecto.

\section{BEPS: ¿una nueva forma de imperialismo fiscal?}

En un trabajo anterior, sostuvimos que la defensa de los patrones fiscales de la OCDE como si fuesen principios generales de tributación internacional sería una forma de imperialismo fiscal. No siendo la OCDE una entidad independiente, pero sí representativa de los intereses de un determinado grupo de países, su política impositiva refleja tales intereses. No es por otra razón que el Modelo de tratado tributario de la OCDE es unánimemente reconocido por reflejar los intereses fiscales de los países desarrollados ${ }^{(27)}$.

Ahora, hay un gran riesgo que, a través del Proyecto BEPS y justificados por las mejores intenciones de protección de la sociedad contra los supuestamente "maléficos" planeamientos tributarios de las empresas

(26) Véase Sergio André Rocha, Tributação de Lucros Auferidos no Exterior (Lei n. 12.973/14) (São Paulo: Dialética, 2014), 86-136.

(27) Véase Sergio André Rocha, "International Fiscal Imperialism and the "Principle" of the Permanent Establishment", Bulletin for International Taxation 2, Vol. 68 (febrero 2014): 83-6. Sergio André Rocha, Tributação Internaional (São Paulo: Quartier Latin, 2013), 88-98. 


\section{El Proyecto BEPS de la OCDE y el Derecho Fiscal Internacional en Brasil The BEPS project of the OECD and the International Tax Law in Brazil}

multinacionales, busquen los países desarrollados exportar su política fiscal para países en desarrollo, como si sus patrones fueran universales y la coordinación a partir de sus intereses un camino sin vuelta.

La actuación de la OCDE en la creación de un patrón tributario global, colgándose la Letra Escarlata en los países por ventura no alineados es inquietante. Hace algunos años que la preocupación con la soberanía fiscal de los países viene creciendo. En este aspecto, el Proyecto BEPS parece traer una preocupación adicional. Es importante que los países latinoamericanos, así como otras naciones en desarrollo, no dejen de defender patrones tributarios que les son favorables para simplemente adherir a modelos que buscan defender los intereses de otros países.

Una de las principales faces de esta cuestión aparece en la propia definición de las situaciones que configuraran una competencia fiscal perjudicial, o sea, de cuáles son los límites (si ellos existen) para la actuación de los países en el diseño de su sistema tributario doméstico.

Obviamente que, en una economía globalizada, los países tienen la obligación de volverse más competitivos con vistas a la atracción de inversiones internacionales, por ejemplo, teniendo una red extensa de tratados sobre la tributación de la renta y del capital, además de tratados para la protección de la inversión. Parece indudable que la existencia de una red tal de acuerdos internacionales no puede ser considerada forma de competencia fiscal perjudicial, por más que pueda ser un factor que vuelva una jurisdicción más atrayente que otras para un inversor extranjero.

Además de esto, entendemos que no todos los alivios fiscales pueden ser considerados abusivos. Véase el caso brasilero de la exención fiscal de los dividendos. La misma fue establecida en 1995, por la Ley 9.249, la cual no tuvo ningún foco de atracción de inversores extranjeros para Brasil. A fines de 2014, repercutieron en el país comentarios hechos por la OCDE en el sentido de que Brasil debería revocar la exención de los dividendos, que esta sería una forma de competencia fiscal preferencial. ¿Será?

Nos parece que, en este caso, estamos delante de la pretensión de una indebida intromisión en la política fiscal brasilera. No hay ninguna evidencia de que la exención de dividendos en Brasil disloque para el país capitales que, si no fuese tal exención, serían invertidos en otro país.

\section{0. ¿Administración tributaria global: objetivo factible?}

Tanto la deseada transparencia fiscal internacional vía intercambio de informaciones, como las medidas más osadas de control de la gestión fiscal de las empresas multinacionales, dependen de la evolución de la cooperación fiscal entre los países, rompiéndose el patrón territorial de las administraciones tributarias (Rocha 2015, 62-67).

Estamos delante de una tendencia de globalización de la administración tributaria y surgen, entonces, cuestiones con respecto a la capacidad de que los países soporten la cantidad adicional de demandas, las cuales son relacionadas no a sus actividades de fiscalización, pero sí al interés de otros países.

Nos parece, considerando el caso de Brasil, que los países no están preparados, técnica o financieramente, para asumir estas nuevas actividades. Tal vez no sea posible, a esta altura, estimar de forma clara cuál será el impacto del nuevo modelo de cooperación sobre la carga de trabajo de las autoridades fiscales de cada país. Con todo, creemos que la efectiva implementación de medidas resultantes del Proyecto BEPS puede traer reales desafíos operacionales para diversos países, en especial países en desarrollo.

\section{1. ¿Cuál es el mejor momento para actuar?}

Una cuestión importante ya es la hora de hacer algo ¿renegociar tratados, o alterar la legislación doméstica-en función del Proyecto BEPS? Entendemos que no. Por más que sea clara la evolución de los trabajos en el ámbito 


\section{Sergio André Rocha}

de la OCDE, parece temprano para que se haga cualquier alteración legislativa en un intento de implementación de potenciales resultados del BEPS.

Tal vez la principal razón para la espera sea el hecho de que la lógica por detrás del Proyecto BEPS es una lógica de armonización y cooperación. Siendo así, lo ideal es aguardar el diseño final del Proyecto para adoptar cualquier medida concreta.

Esta parece ser la orientación de las autoridades fiscales brasileras. Por ejemplo, en 2014, fue editada la Ley 12.973 que reformó las reglas brasileras de tributación de ganancias controladas en el exterior. Esta ley autorizó al inversor brasilero a consolidar los resultados de sus inversiones en el exterior hasta 2022 (artículo 78). Según manifestaciones informales de la Receta Federal, este plazo fue establecido porque se espera que hasta allá se tenga el diseño final del Proyecto $\mathrm{BEPS}$ en lo que se refiere a las legislaciones CFC.

Siendo así, lo que todo indica la posición brasilera será, como ya mencionados, en el sentido de aguardarse el resultado final del Proyecto para entonces definir si el mismo tendrá algún impacto en Brasil.

\section{Conclusión}

El siglo XXI trajo una nueva era para la tributación internacional. Las iniciativas que se materializaron en este período colocaron en discusión los principios de la tributación internacional del siglo $X X$, remanecientes de los primeros trabajos de la Sociedad de las Naciones. Con todo, las modificaciones que hoy se discuten deben ser consideradas con mucha cautela, especialmente por los países en desarrollo.

Por más que se haya buscado el alineamiento de tales países con iniciativas como el Proyecto BEPS de la OCDE, el hecho es que la voz de estos países no se hace oír tan alta en las discusiones principales sobre el modelo que resultará del Proyecto.

Por esta razón, los países en desarrollo no deben subscribir inmediatamente las sugerencias presentadas, las cuales pueden, eventualmente, contrariar sus intereses fiscales domésticos. Los países latinoamericanos tienen una larga tradición de pensamiento al respecto de la tributación internacional y deben hacer lo máximo posible para evitar que su soberanía fiscal sea empequeñecida en razón de una pretendida armonización con lo que sería el "patrón internacional", que en verdad es el patrón definido por los países desarrollados.

\section{Referencias Bibliográficas}

Avi-yonah, Reuven S. 2000. Globalization, Tax Competition, and the Fiscal Crisis of the Welfare State. Harvard Law Review. Vol. 113: 1575-77.

Brauner, Yariv. 2014. BEPS: An Interim Evaluation. World Tax Journal 6 (febrero): 37.

De Andrade, André Martins. 2008. Tributação Internacional da Renda Empresarial. Belo Horizonte, Editora Fórum.

Dornelles, Francisco Oswaldo Neves. 1978. Acordos para Evitar a Dupla Tributação da Renda. Revista de Direito Tributário 3 (eneromarzo): 253-254.

Easson, Alex. 2000. Do we still need Tax Treaties? Bulletin for International Taxation, Amsterdam. Vol. 54: 619.

Lang, Michael y Jeffrey Owens. 2014. The Role of Tax Treaties in Facilitating Development and Protecting the Tax Base. WU International Taxation Research Paper Series 03.

http://papers.ssrn.com/sol3/papers. cfm?abstract_id=2398438.

Organización de las Naciones Unidas. Subcommittee on Base Erosion and Profit Shifting Issues for Developing Countries. Comments from Brazil. http://www.un.org/ esa/ffd/wp-content/uploads/2014/10/ta-BEPSCommentsBrazil.pdf.

Organización para la Cooperación y el Desarrollo Económicos (OCDE). 1998. Harmful Tax Competition: An Emerging Global Issue. Paris: OEDC. 


\section{El Proyecto BEPS de la OCDE y el Derecho Fiscal Internacional en Brasil The BEPS project of the OECD and the International Tax Law in Brazil}

2012. Brazil: Peer Review Reports, Phase 1, Legal and Regulatory Framework. Paris: OECD.

2013. Brazil: Peer Review Reports, Phase 2, Implementation of the Standard in Practice. Paris: OECD.

2014. Developing a Multilateral Instrument to Modify Bilateral Tax Treaties. Paris: OECD.

Pires, Manuel. 1989. International Juridical Double Taxation of Income. Amsterdam: Kluwer.

Pistone, Pasquale. 2014. Coordinating the Action of Regional and Global Players during the Shift from Bilateralism to Multilateralism in International Tax Law. World Tax Journal 6 (febrero): 3-4.

Pistone, Pasquale y otros, coords. 2012. The Impact of the OECD and UN Model Conventions on Bilteral Tax Treaties. New York: Cambridge University Press.

Piketty, Thomas. 2014. O Capital no Século $X X I$. Rio de Janeiro: Intrínseca.

Quiroga, Roberto y Alexsandro Broedel, coords. 2015. Controvérsias JurídicoContábeis (Aproximações e Distanciamentos): Volume VI. São Paulo: Dialética.

Rezende, Condorcet, org. 1999. Estudos Tributários. Rio de Janeiro: Renovar

Rocha, Sergio André Rocha. 2007. Treaty Override no Ordenamento Jurídico Brasileiro. São Paulo: Quartier Latin, 2007.

2009. Interpretation of Double Taxation Conventions: General Theory and Brazilian Perspective. The Netherlands: Kluwer.
Latin.

2012. Tributação Internacional. São Paulo: Quartier

2013a. Tributação Internaional. São Paulo: Quartier Latin.

2013b. Interpretação dos Tratados para Evitar a Dupla Tributação da Renda. 2ª ed. São Paulo: Quartier Latin.

2014a. Tributação de Lucros Auferidos no Exterior (Lei n. 12.973/14). São Paulo: Dialética.

2014b. International Fiscal Imperialism and the "Principle" of the Permanent Establishment. Bulletin for International Taxation 2. Vol. 68 (febrero): 83-6.

2015. Troca Internacional de Informações para Fins Fiscais. São Paulo: Quartier Latin.

Schoueri, Luis Eduardo. 2008. Contribuição à História dos Acordos de Bitributação: a Experiência Brasileira. Revista Direito Tributário Atual 22: 267.

Serrano Antón, Fernando. 2010. La Resolución de Conflictos en el Derecho Internacional Tributario: Procedimiento Amistoso y Arbitraje. Navarra: Civitas.

Takano, Caio Augusto. 2014. Erosão da Base Tributável e a Transferência de Resultados: o Caminho para o Multilateralismo e a Novas Perspectivas à Soberania Fiscal. Revista Direito Tributário Atual 32: 65.

Uckmar, Victor, Marco Aurélio Greco y Sergio André Rocha. 2012. Manual de Direito Tributário Internacional. São Paulo: Dialética.

Vita, Jonathan Barros. 2010. As Convenções para Evitar a Dupla Tributação Brasileiras: Técnicas de Negociação e Análise Estrutural Segundo os Modelos OCDE e ONU. Revista Direito Tributário Atual 24: 303-319.

Xavier, Alberto. 2010. Direito Tributário Internacional do Brasil. $7 \underline{a}$ ed. Rio de Janeiro: Forense. 